\section{Infant toilet training}

Dear Editor,

We read with great interest the article by Mota \& Barros on toilet training in Brazil. ${ }^{1}$ The authors expressed their concern regarding early toilet training and possible adverse events. They based these concerns on two articles ${ }^{2,3}$; we read both articles thoroughly and did not find any mention of adverse events connected with early toilet training. On the contrary, Luxem \& Christophersen concluded that "empirical data suggest that early toilet training is physiologically possible and behavioral techniques might be developed to train the younger child and that they can be made practical and socially valid," 2 and Taubman ${ }^{3}$ noted an "association of this behavior [stool toileting refusal] with toilet training at a later age." Moreover, Taubman refers to pre-Brazelton "coercive toilet training practices that were prevalent in the United States." Assisted infant toilet training (AITT) and related methods are dramatically different in that there is no enforcement involved; instead there is gentle attention given to the child's elimination signals and needs. ${ }^{4}$

Mota \& Barros ${ }^{1}$ wrote, "we know that it is not possible to accelerate the development and myelination of nerve fibers, which are necessary to acquire this control, and that the child needs cognitive development to be able to understand the mechanisms involved in acquisition of urinary habits, and also how to adapt to the local culture and socialize." They base these claims on an article by Hellstrom et al., ${ }^{5}$ but this article is a survey and not a research of myelinization or development of nerve fibers. While Brazelton stressed that myelinization of the pyramidal tracts of the central nervous system must be complete, occurring in his opinion between 12-18 months, Luxem \& Christophersen ${ }^{2}$ argue it is probably present by the time a child crawls, and, based on cross-cultural studies, they conclude that toilet readiness is determined more by environment than neuroanatomy. Moreover, Hellstrom et al. suggest in another article $e^{6}$ that late rather than early toilet training actually might result in bladder dysfunction.

Methods of early toilet training such as AITT (also called "elimination communication") are widely used in Asia and Africa. Various studies have shown that toddlers and even babies are capable of staying dry when allowed other options more befitting their developmental status. ${ }^{4,7}$ Despite their underdeveloped nervous systems, babies can grasp the mechanisms of urinary functioning well enough to display elimination signals and satisfaction when offered a potty. ${ }^{4,7} \mathrm{~A}$ neonate will squirm or cry when feeling the urge to empty its bladder or bowels. An older baby will gesture, and if possible crawl in the direction of a potty; a walking toddler may walk to a potty and sit down. When a baby is diapered, these signals are misinterpreted and ignored. An attentive parent can recognize these gestures and assist the child. ${ }^{4}$

An international study of $\mathbf{2 8 6}$ children who started toilet training during the first year of life revealed that over $90 \%$ showed elimination signals; mean completion ages for daytime dryness and bowel control were lower than 18 months, and no negative side effects were reported. ${ }^{7}$ Compared with Western toilet training (started around 2 years of age), stool toileting refusal in AITT drops from 22 to $12 \%{ }^{7}$

We believe that AITT offers a healthy alternative to contemporary toilet training. The child can enjoy more mobility without a cumbersome diaper, will suffer less skin rash and may develop better bladder function, ${ }^{6}$ while child-parent communication is enriched, and ecological damage caused by disposable diapers is reduced.

The current ecological and economical situation calls for such an alternative, especially in countries where a large part of the population has limited financial resources, like Brazil.

\section{References}

1. Mota DM, Barros AJ. Toilet training: situation at 2 years of age in a birth cohort. J Pediatr (Rio J). 2008;84:455-62.

2. Luxem M, Christophersen E. Behavioral toilet training in early childhood: research, practice, and implications. J Dev Behav Pediatr. 1994;15:370-8.

3. Taubman B. Toilet training and toileting refusal for stool only: a prospective study. Pediatrics. 1997;99:54-8.

4. Sun $M$, Rugolotto $S$. Assisted infant toilet training in a Western family setting. J Dev Behav Pediatr. 2004;25:99-101.

5. Hellstrom AL, Hanson $E$, Hansson $S$, Hjälmås $K$, Jodal U. Micturition habits and incontinence in 7-year-old Swedish school entrants. Eur J Pediatr. 1990;149:434-7.

6. Hellstrom AL. Influence of potty training habits on dysfunctional bladder in children. Lancet. 2000;356:1787.

7. Rugolotto S, Sun M, Boucke L, Calò DG, Tatò L. Toilet training started during the first year of life: a report on elimination signals, stool toileting refusal and completion age. Minerva Pediatr. 2008; 60:27-35. 
doi:10.2223/JPED. 1868

No conflicts of interest declared concerning the publication of this letter.

\section{Sahar Tali}

MD, MSc. Department of Family Medicine, Hebrew University, Jerusalem, Israel.

\section{Schramm-Urbach Efrat}

BA. Ben-Gurion University, Israel.

\section{Laurie Boucke}

BA. White-Boucke Publishing, Colorado, USA.

\section{Simone Rugolotto}

MD. Division of Pediatrics, Legnago Hospital, Legnago, Italy.

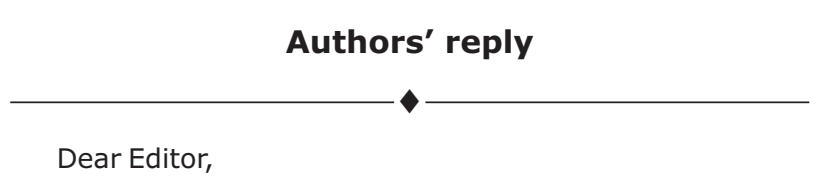

We are grateful for the interest that Dr. T. Sahar and colleagues have shown in our work. One of our objectives in writing a series of articles on this subject is to draw the attention of both pediatricians and researchers to the issue of toilet training. This is a very stimulating subject in which cultural variations intermingle with physiological and behavioral characteristics.

In 2003, while conducting research into micturition habits, ${ }^{1}$ we detected that there had been an increase in the prevalence of voiding dysfunction among preschool and school aged children over recent years. Some of the articles that we reviewed suggested that toilet training might be a possible predictive factor for voiding disfunction. We therefore decided to review the literature ${ }^{2}$ and to conduct a longitudinal study of the subject using data from a cohort of children born in the city of Pelotas in 2004 and who are being followed. To date we are in possession of data relating to assessments of these children at 12 and 24 months, which have led to two articles. ${ }^{3,4}$

In order to be in a position to reply to the questions raised by Tali et al., it is necessary to first point out that our study took into account the strategies actually used by Brazilian mothers, which have nothing to do with the assisted infant toilet training techniques (AITT) that these authors recommend. In the Brazilian setting, which is probably very similar to many other Western countries, we observed that a considerable percentage of the unsuccessful attempts at toilet training were initiated before infants reached 18 months of age. Our adjusted statistical analysis demonstrated that previous unsuccessful attempts at toilet training were associated with a reduced chance of being toilet trained by two years of age. Summing up, our results suggest that starting training before 18 months of age may delay the acquisition of bladder and bowel control. Of course, we are not dealing with data relating to other cultures, where completely different strategies are described. ${ }^{5}$ There is still limited evidence that this particular strategy can be used in a western cultural context. ${ }^{6}$
Our concerns with relation to the possible adverse effects of toilet training are not limited to premature attempts at training, but rather include a variety of inappropriate forms of training, like late toilet training, dispensing with the use of a child-sized toilet seat and/or a foot rest and also coercive and punitive attitudes.

With relation to the issue of neurological maturity and the acquisition of certain abilities, we do believe that these are important factors and that the abilities listed in previous publications ${ }^{2}$ and dealt with by Schum et al. ${ }^{7}$ are a guide here. However, it is important to point out that the ultimate objective of our approach to toilet training is for children to attain an independent status in which they are capable of maintaining themselves dry and clean without aid or with aid limited to specific tasks.

Finally, we reiterate that we are not criticizing the AITT method and that we will wait for further scientific evidence of its results, in terms of success of its use and the absence of undesirable effects. Our research is also ongoing and we are currently evaluating data referring to the now 4-year-old children, in order to observe whether inadequate toilet training may indeed be related to symptoms of voiding dysfunction. We need this evidence urgently so as to enable pediatricians to correctly advise mothers with relation to the most appropriate strategies for toilet training safely without leading to future problems, bearing in mind that existing methods have not been adequately tested or compared with one another.

\section{References}

1. Mota DM, Victora CG, Hallal PC. Investigation of voiding dysfunction in a population-based sample of children aged 3 to 9 years. J Pediatr (Rio J). 2005;81:225-32.

2. Mota DM, Barros AJ. Toilet training: methods, parental expectations and associated dysfunctions. J Pediatr (Rio J). 2008; 84:9-17.

3. Mota DM, Barros AJ. Treinamento esfincteriano precoce: prevalência, características materna da criança e fatores associados numa coorte de nascimentos. Rev Bras Saude Mater Infant. 2008;8:103-11.

4. Mota DM, Barros AJ. Toilet training: situation at 2 years of age in a birth cohort. J Pediatr (Rio J). 2008;84:455-62.

5. deVries MW, deVries MR. Cultural relativity of toilet training readiness: a perspective from East Africa. Pediatrics. 1977;60: 170-7.

6. Rugolotto S, Sun M, Boucke L, Calo DG, Tato L. Toilet training started during the first year of life: a report on elimination signals, stool toileting refusal and completion age. Minerva Pediatr. 2008; 60:27-35.

7. Schum TR, Kolb TM, McAuliffe TL, Simms MD, Underhill RL, Lewis M. Sequential acquisition of toilet-training skills: a descriptive study of gender and age differences in normal children. Pediatrics. 2002;109:E48. 
doi: $10.2223 /$ JPED. 1869

No conflicts of interest declared concerning the publication of this letter.

\section{Denise M. Mota}

Mestre. Médica nefrologista pediátrica, Programa de Pós-Graduação em Epidemiologia, Universidade Federal de Pelotas (UFPel), Pelotas, RS, Brazil.

\section{Aluisio J. D. Barros}

Doutor. Professor associado, Programa de Pós-Graduação em Epidemiologia, UFPel, Pelotas, RS, Brazil.

\section{Increased risk of pyrexial illness with higher doses of iron supplementation}

\section{Dear Editor,}

The study conducted by da Silva et al. sets out to investigate the relative advantages and disadvantages of three different iron prophylactic regimens. ${ }^{1}$ The authors claim that the findings about an association of iron supplementation and enhanced vulnerability to infections are controversial, and they also claim that the groups of their study did not show differences in morbidity. A close look at the data provided by the authors reveals that, if one compares the group with 2 $\mathrm{mg} / \mathrm{kg} /$ day of iron supplementation with the other groups, who had $1 \mathrm{mg} / \mathrm{kg} /$ day iron or less, pooled into one group, the incidence of fever was significantly greater in the group with higher iron intake (28/36), compared to the incidence in the pooled group with half or less of this iron intake $(42 / 77)(p=$ 0.03 , chi-square test). The majority of comparisons (seven out of 10) in incidence of infectious diseases between the three groups reveals an (albeit not statistically significant) increased incidence in the group with $2 \mathrm{mg} / \mathrm{kg} /$ day of iron. Larger sample sizes may have revealed a statistically significant difference for each comparison. Such a difference became evident in the largest randomized, controlled trial of iron supplementation by Sazawal et al. involving 24,076 children. ${ }^{2}$ That study, the largest to date, concluded that, in areas with high rates of malaria, iron and folic acid supplementation can result in a $12 \%$ increased risk of severe illness and death. Analysis of results for infection-related causes included confirmed febrile illness not meeting definitions for malaria (e.g., pneumonia, sepsis, meningitis, measles, pertussis) and revealed that, compared with placebo, the iron supplemented groups had a significantly higher risk for serious adverse events (1.32, $1.10-1.59)$, deaths (1.61, 1.03-2.52), and admissions to hospital $(1.28,1.05-1.55)$ due to these causes. The findings were significant enough for the data and safety monitoring board to stop the trial of iron and folic acid supplementation prematurely. Subgroup analysis of this trial showed that these effects are mainly due to increased risk of infectious complications in children who were not iron-deficient at the beginning of the trial. Based on this trial, it is possible to conclude that prophylactic iron supplementation in children who are not iron-deficient in areas with high incidence of infectious diseases cannot be justified.

\section{References}

1. da Silva DG, Franceschini SC, Sigulem DM. Growth in non-anemic infants supplemented with different prophylactic iron doses. J Pediatr (Rio J). 2008;84:365-72.

2. Sazawal S, Black RE, Ramsan M, Chwaya HM, Stoltzfus RJ, Dutta $A$, et al. Effects of routine prophylactic supplementation with iron and folic acid on admission to hospital and mortality in preschool children in a high malaria transmission setting: community-based, randomised, placebo-controlled trial. Lancet. 2006;367:133-43.

doi:10.2223/JPED. 1865

No conflicts of interest declared concerning the publication of this letter.

\section{Helena Watson}

MD. Luton \& Dunstable Hospital NHS Foundation Trust, Luton, England.

\section{Michael Eisenhut}

MB. B. Chir. Luton \& Dunstable Hospital NHS Foundation Trust, Luton, England.

\section{Authors' reply}

\section{Dear Editor,}

We appreciate the comment made by researchers on our paper. ${ }^{1}$ However, we admit that the differences in morbidity between iron-supplemented groups should be interpreted with caution, because possible confounding variables were not controlled. It should also be underscored that, unlike the study cited by the researchers, ${ }^{2}$ whose region is endemic to malaria, the investigated population belongs to a non-endemic area. Therefore, we believe other studies are necessary to look into the relationship between morbidity and prophylactic iron supplementation in similar populations. Some authors have observed that iron supplementation does not seem to increase the general risk for infection in non-endemic areas of malaria, as opposed to endemic areas, where such risk apparently exists. $^{3,4}$ The debates about this issue are of great importance as they stress the need to identify the actual risks and benefits of using prophylactic iron supplementation as a preventive measure against iron deficiency in the first years of life. In addition, based on these data, one should also assess whether the confirmation of specific risks justifies keeping the general population from receiving the benefits of this supplementation.

\section{References}

1. da Silva DG, Franceschini SC, Sigulem DM. Growth in non-anemic infants supplemented with different prophylactic iron doses. J Pediatr (Rio J). 2008;84:365-72. 